\title{
MAKING BABIES HEALTHIER BY PROVIDING A MANAGED CARE OPTION TO CALIFORNIA'S POOR
}

\author{
Tania Barham \\ UC Berkeley \\ Paul Gertler \\ UC Berkeley and NBER \\ and \\ Kristiana Raube \\ UC Berkeley
}

May 1, 2003

Contact information: Tania Barham Department of Agriculture Economics, University of California Berkeley 94720, email: barham@are.berkeley.edu. Paul Gertler, Haas School of Business, University of California Berkeley, 94720-1900, email: gertler@haas.berkeley.edu. Kristiana Raube, Haas School of Business, University of California Berkeley, 94720-1900, email: raube@haas.berkeley.edu. The authors we like to thank Alain de Janvry, Claudio Ferraz, Frederico Finan, Guido Imbems, Karen Macours, Craig McIntosh, Xiangyi Meng, Elizabeth Sadoulet for their helpful comments and input. We would also like to thank the California Policy Research Center for their financial support as well as Marcine Craine and Jim Kleine from the California Department of Health Services for their help with the programmatic details about the manage care mandates and data. All mistakes are solely those of the authors and the usual disclaimers apply. 


\section{Introduction}

During the 1990s, California undertook a sweeping change in its Medicaid program by shifting over half of the beneficiaries from fee-for-service into managed care. In fact, by 2001, over 5.8 million Medi-Cal recipients (52 percent) were enrolled in managed care. California was not alone as 57 percent of all Medicaid recipients nation-wide were in managed care by 2002 (Figure 1). ${ }^{1} \quad$ States embraced managed care in part as a solution to control skyrocketing costs following private sector success with using managed care to control cost during the 1980s (Kaestner, 2002), and as a means of improving access to quality primary care for low-income groups (McCall et al., 2000). Indeed, access to quality care has been a problem for fee-for-service Medi-Cal patients (Menges et al. 2001; Coburn et al. 1999). In fact many pregnant Medi-Cal beneficiaries started prenatal late and most used providers associated with the county public health care systems.

In this paper, we investigate the impact of California mandating that MediCal beneficiaries be given a managed care option on their access to prenatal care and birth outcomes. We take advantage of the fact that California mandated that Medi-Cal recipients in 22 out of 58 counties be provided with a managed care option (Table 1). In addition, counties began implementing the mandate at different times between 1994 and 2000. This variation in time and geography provides us with a potential instrument for estimating the impact of managed care on the health outcomes of California's poor using a difference in differences approach.

We also examine the importance of offering an existing mainstream commercial managed care option as opposed a county organized health care system, which is a noncommercial managed care option that contracts with the network of mainly public providers traditional used by Medi-Cal beneficiaries. A number of counties implemented County Organized Health Systems (COHS) that provide a single county organized managed care option, whereas others used the Two Plan Model (TPC) that offers choice between a mainstream commercial plan and the county organized option.

Using longitudinal birth record information from California's vital statistics from 1991 through 2001 we find that offering managed care reduced the number of low-birth weight and premature births in TPC counties, but not in COHS counties. These findings are especially remarkable given the overall rise in low-birth weight and premature babies during the 1990s (CDC, 2002). Moreover, that managed care had positive health benefits is important for public policy given that there do not appear to be any cost savings for Medi-Cal from managed care (Duggan, 2002).

These results also highlight the importance of providing a mainstream commercial managed care option to the improving the health of babies in poor populations. The commercial groups effectively mainstream Medi-Cal beneficiaries into care equivalent to mothers with higher incomes. Moreover, the commercial option in the TPC model may

\footnotetext{
${ }^{1}$ Presently, all states except for Alaska and Wyoming have some form of Medicaid managed care (Kaiser Commission on Medicaid and the Uninsured, 1999).
} 
have put competitive pressure on the non-commercial managed care option to provide better quality of care.

The paper is organized as follows. In section 1 we describe the pathways by which managed care might influences birth outcomes in poor populations and the existing evidence. We describe the main managed care models in California in Section 2. Section 3 describes the construction of the data, the treatment and comparison groups, and the dependent variables. The identification strategy is explained in Section 4 while and Section 5 presents the validity of the comparison groups and summary statistics. The results are discussed in Sections 6 and Section 7 concludes the paper.

\section{Pathways}

Our results are consistent with the design of managed care, which attempts to control costs and improve access to quality health care by changing the financial incentives and the organization of health care. Under managed care, members choose a provider and the provider receives a fixed payment per month for the medical care of each member. Providers keep or lose the difference between the payment and the cost of care. This payment system, called capitation, provides an incentive to keep costs low by reducing unnecessary care and by keeping members healthy through preventive care.

This emphasis on prevention means that members do not wait until they are sick to find a provider and enables the members and providers to develop long-term relationships. Low-income populations are especially likely to benefit from managed care because for many of them it is the first time they obtain access to regular and ongoing mainstream health care. Moreover, in the case where Medi-Cal beneficiaries take up the commercial option, they for the first time get access to the same quality of care that higher income families have, which is a substantial improvement.

Managed care is likely to have its greatest impact on birth outcomes where prevention (e.g., early prenatal care) is key to having healthy babies. Indeed, examining the impact of California's Medi-Cal managed care option on prenatal care and birth outcomes provides a good test of the managed care program's ability to improve access and quality of health care for low-income populations.

In addition to the incentives to invest in prevention, an additional mechanism by which managed care might improve health outcomes is through provider competition for patients. One-way providers can compete for a patient is by improving the quality of their services. Our analysis sheds light on the importance of competition in managed care on health outcomes. Our findings show that health outcomes improved for the Two Plan Model whereas there was little change in the model without competition. This suggests that in addition to the preventive care incentives imbedded in capitation, choice and competition are additional important mechanisms by which managed care improves health outcomes. 
Past results on managed care's ability in improve quality and access for the commercial population are mixed. (Luft 1981, Miller and Luft 1994, Miller and Luft, 2002). These uneven findings may be a result of the large number of different types of managed care plans being studied, each often serving very different populations. Indeed, a controlled experiment performed by RAND on the commercial population found that managed care lead to no change in quality (Manning et al. 1984). Our results of improved quality and access for California's Medicaid population may a further proof of managed care's ability to mainstream health care for the poor.

Despite the expansion of Medicaid managed care, there has been little rigorous analysis of the impact on quality of care for this population. The analyses of the impact on birth outcomes to date are mixed. A number of studies use cross-sectional analysis that could be confounded by selection bias issues and therefore problems of establishing causality (e.g. Oleske et al 1998, Levison and Ullman 1998). A number of other analyses are based on longitudinal data, but do not use comparison groups to account for secular trends (e.g. Ray et al. 1998, Griffen et al. 1999). While Kreiger et al. use control groups, they lack pre-intervention data.

Two studies use difference in differences approaches. (Kaestner et al 2002, Duggan 2002). On the national level, Kaestner et al. find that Medicaid managed care has not significantly impacted infant health. The authors perform difference in differences analyses but have difficulties because they cannot clearly identify which births were insured by Medicaid in their data.

In California, Duggan uses 1993 to 2000 California hospital discharge data to examine the impacts of the managed care mandates on avoidable hospitalizations among children and infant death. He uses the FFS Medi-Cal counties as a control group and finds that child health status remained unchanged, and that infants were no less likely to die.

Duggan (2002) also evaluates the impact of the shift from fee-for-service to managed care on California state health expenditures. He finds a 15 to 20 percent increase in county Medi-Cal spending was associated with the switch from fee-for-service to managed care. However, he also finds almost no increase in government expenditures in those counties where 35 percent or more of their recipients were already enrolled in an $\mathrm{HMO}$ at the time of the mandate, suggesting the cost rise is likely to be temporary.

In these two papers the authors were unable to test if their control group is a valid counterfactual. Although a definitive test is impossible since we will never be able to know what would have happened to the treated had they not been treated, preintervention data can be used to test if the slope of the outcomes variables for the treatment and control groups are similar. We therefore cannot be sure if their results are due to the initiation of managed care for the Medicaid population or other factors, which may have caused the groups to have differing trends in the growth rate of the outcome variables. In our paper we pay careful attention to choosing the correct control group. We identify three possible control groups - the Medi-Cal fee-for-service patients, the uninsured in Medi-Cal managed care counties, and the commercially insured in Medi-Cal 
managed care counties - and test their appropriateness as counterfactuals using preintervention data. We choose different control groups for the COHS and the TPC treatment groups.

\section{Medi-Cal Managed Care}

Medicaid managed care is not new to California, as Santa Barbara began such a program in 1983. However, starting in 1993, the state mandated that 22 out of the State's 58 counties provide their Medi-Cal beneficiaries with a managed care option. Between 1994 and 2001, these 22 counties implemented mandated managed care for their Medi-Cal beneficiaries (Figure 2 and Table 1). The fact that managed care option was not mandated in all counties provides us with potential comparison groups. By January 2002, over 5.8 million Californians or 52 percent of all Medi-Cal recipients were part of California's Medi-Cal managed care program.

Not all managed care counties use the same model. Almost all of Medi-Cal managed care members were enrolled in one of two programs: the Two-Plan Model (TPC) or County Organized Health System (COHS). TPC enrolls the largest number, 42 percent of all Medi-Cal recipients, while, COHS accounts for 8 percent of all recipients. There are now seven COHSs covering eight counties in California and 12 counties with TPC models (Table 1).

COHS was the first of the two main managed care models to be enacted in California. In this model the county sets up a non-commercial County Operated Health that is responsible for providing medical services to all the Medi-Cal beneficiaries under its jurisdiction. The county operates it as an independent public entity that meets the insurance regulatory requirements for pre-paid health plans. This entity contracts with the network of providers who traditional provided care to MediCal beneficiaries, most of which are in the county public health care system. The California State Medi-Cal Assistance Commission pays the COHS a prepaid capitated rate each month for each Medi-Cal recipient (McCall et al. 2001).

In 1995, 12 counties were designated to participate in the state's TPC managed care program. Under TPC, the county's Medi-Cal beneficiaries can choose between a commercial managed care plan and a county-developed plan similar to COHS called the local initiative that is intended to preserve the network of traditional safety net providers (McCall et al. 2001). Capitation rates are set in the same manner as in the COHS counties.

The Medi-Cal managed care mandates require that for almost all health care services, Medi-Cal beneficiaries use the county-endorsed managed care providers. However, prenatal care, deliveries, and health care for infants are exceptions to this rule. The TPC plans allow pregnant women to obtain a medical exemption so they can choose to opt-out of the managed care plan and seek prenatal care and delivery services from a provider of their choice. Under the COHS plan, non-welfare beneficiaries who do not normally 
receive Medi-Cal may qualify to receive prenatal care, delivery services, and health care for their newborns from Medi-Cal when they become pregnant. To ensure continuity of care for this expanded group, the COHS plans allow these pregnant women to opt-out of the otherwise required managed care plan and seek prenatal care and delivery services from a provider of their choice on a fee-for-service basis. Despite the opt-out option, 30 percent of Med-Cal births were covered by managed care by 2000 .

\section{The Data}

Our empirical analysis is based on 1991 to 2001 California data from the Birth Statistical Masterfile that is available through the California Department of Health Services, Office of Health Information and Research. This database contains information on all live births reported on birth certificates in California providing us with over 4,006,642 observations. It includes race, education and zip code information related to the mother and father, as well as birth outcomes and insurance status data.

In this study we test for the impact of the managed care option on access and quality of prenatal care for pregnant women. We use utilization of prenatal care and birth outcomes as proxies for quality and access to care. In particular, we focus on four dependent variables: the month prenatal care began (Month Start), the percent of women that had their first prenatal care visit in the first trimester of their pregnancy (First Trimester), low birth weight (LBW), and the incidence of preterm birth

Our analysis relies on two birth outcomes to measure the quality of care provided to pregnant women, birth weight and gestational age. Both these variables are seen as important markers for a child's health and future. Studies on LBW infants $(<2500$ grams) have shown that these children have a higher infant mortality rate, lower education levels, poorer health as children and adults, and lower income earnings (Talyor et al. 2000, Strauss 2000, Elgen et al. 2002, Donohue et al. 2002) ${ }^{2}$. We also examine changes at lower end of the distribution of birth weight, extremely low birth weight (xLBW), which includes babies that are 1000 grams or less.

Preterm delivery, the birth of an infant before 37 gestational weeks are completed, is the principal determinant of low birth weight and is the factor considered most responsible for the relatively high infant mortality rate in the United States compared to other industrialized countries (Paneth, 1995). Unfortunately, the causes of preterm delivery are not well understood. Some pathways thought to be important are genetic factors, stress, and inflammatory response and hemorrhage into the myometrium (Mattison, 2001). Within the United States, the preterm delivery rate varies widely by race with African Americans suffering the highest rates and the Asian population experiencing the lowest. Like LBW we also examine babies at the lower end of the distribution, in particular those that are very premature, less than 33 gestational weeks at birth.

\footnotetext{
${ }^{2}$ Chay et al. (2002) questions these beliefs, and argues that the 5-minute APGAR scores may in fact be a better measure of infant health. Due to data limitations we cannot include APGAR scores in our study.
} 


\section{Identification and Estimation Strategy}

Our objective is to identify the average effect of making managed care available on birth outcomes in the counties where managed care was mandated (i.e. the average impact of treatment on the treated). Specifically, we are interested in comparing birth outcomes when managed care is available compared to the counterfactual-i.e. birth outcomes when managed care is unavailable in the treatment areas at the same point in time. Since the counterfactual is never observed, we must estimate it. In principle, we would like to randomly assign managed care across counties and compare the average outcomes of the two groups. In the absence of a controlled randomized-trial we are forced to turn to nonexperimental methods that mimic it under reasonable conditions.

A major concern is that the counties that were chosen for the managed care mandates could be different from the counties that were not chosen, and that these differences may be correlated with birth outcomes. For example, richer counties with more health care infrastructure where birth outcomes were better may have been the ones that received the mandates. In this case, the correlation between managed care and birth outcomes would be confounded with the wealth effect. In principle, many of the types of (unobservable) characteristics that may confound identification are those that vary across counties, but are fixed over time. A common method of controlling for time invariant unobserved heterogeneity is to use panel data and estimate difference in differences models.

Therefore, without the benefit of a controlled randomized trail, we turn to a difference in differences approach, which compares the change in outcomes in the treatment group before and after the intervention to the change in outcomes in the control group. ${ }^{3}$ By comparing changes, we control for observed and unobserved time-invariant county characteristic s that might be correlated with the managed care decision as well as with birth outcomes. The change in the control group is an estimate of the true counterfactual, that is, what would have happened to the treatment group if there were no managed care mandates. Another way to state this is that the change in outcomes in treatment areas controls for fixed characteristics and the change in outcomes in the control areas controls for time varying factors that are common to both control and treatment areas.

\section{Empirical Specification}

We compute the difference in differences estimate using a linear regression of the form:

$$
Y_{i j t}=\alpha_{j}+\beta_{t} t+\gamma M C_{j t}+\lambda t T_{j}+\sum_{k} \delta_{k} X_{i t k}+u_{i t}
$$

Where:

$Y_{i j t} \quad=$ birth outcome for birth $i$ in zip code $j$ in year $\mathrm{t}$

$\alpha_{j}{ }^{\prime} s=$ zip code fixed effects

$\beta_{t}{ }^{\prime} s \quad=$ year fixed effects

\footnotetext{
${ }^{3}$ The difference in differences estimator is one of the most widely used in the evaluation literature (see, among others, Angrist, 1995; and Heckman et al, 2000).
} 


$$
\begin{array}{ll}
t & =\text { year } \\
T_{j} & =1 \text { if the county in which zip code } \mathrm{j} \text { is located will offer managed care at } \\
& \text { some point in time } \\
M C_{j t} & =1 \text { if managed care was offered to Medi-Cal beneficiaries in zip code } j \text { in } \\
& \text { year } t \\
X_{i t k}{ }^{\prime} s & =\text { socio-economic characteristics of parents } \\
\varepsilon_{i t}{ }^{\prime} s & =\text { disturbance terms. }
\end{array}
$$

The coefficient $\gamma$ is the difference in differences estimate of the average impact of making managed care available to Medi-Cal beneficiaries on birth outcomes. Since few women give birth in every year it is not feasible to have a mother fixed effect. Rather we include zip code fixed effects, which controls for zip code level factors that do not change over time. We do, however, include a set of birth specific socioeconomic controls such as the age and education level of the mother and father. We also include year fixed effects, which control for time varying factors that are common to both control and treatment areas. Finally, we include a linear time trend interacted with whether a county will become a treatment county at some point in time to allow for different time trends.

The above specification assumes that the program had an immediate impact and that the level of the impact was constant over time. An alternative hypothesis is that the program took some time to implement, and time for beneficiaries and providers to learn how best to use it. In order to allow for this possibility we estimate a more general version of equation (1):

$$
Y_{i j t}=\alpha_{j}+\beta_{t} t+\sum_{s} \gamma_{s} M C_{j t}^{s}+\sum_{k} \delta_{k} X_{i t k}+u_{i t}
$$

where $s$ is the number of years that managed care has been available in a zip code, $M C_{j t}^{s}$ equals 1 if managed care was available $s$ years in zip code $j$ in year $t$.

\section{Threats to Validity of Identification}

There are three critical assumptions for $\gamma$ to be an unbiased estimate of the program impact. The first is the assumption that the change in birth outcomes in comparison areas is an unbiased estimate of the counterfactual-i.e. what would have happened to birth outcomes in the treatment areas if managed care had not been offered. While we cannot directly test this assumption, we can test whether the secular time trends in the control and treatment counties were the same in the pre-intervention periods (Heckman and Hotz, 1989). If the secular trends are the same in the pre-intervention periods, then it is likely that they would have been the same in the post intervention period if the treated counties had not offered managed care.

The second concern is that there may be unobserved characteristics that vary across time and space, which are correlated with both birth outcomes and the mandates. For example, it could be that the areas where managed care was mandated were also hit by positive 
economic shocks so that the socio-economic mix of Medi-Cal beneficiaries evolved differently over time. We address this concern by directly controlling for socio-economic characteristics of the parents.

The third concern is that the impact of treatment on the treated may not be homogenous across beneficiaries, but rather vary as a function of their characteristics. For example, the impact of managed care may matter for mothers who are uneducated. In this case, simple difference in differences estimates may suffer from two additional sources of bias (Heckman et al, 1997, and Heckman et al, 1998a). The first bias arises when there are no comparison observations with comparable characteristics for treatment observations and vice versa. In this case, there are treatment and control observations that do not have common support of observable characteristics, $\mathbf{x}$. The second bias may arise from different distributions of the vector of observable variables that affect birth outcomes $(\mathbf{x})$ within the treatment and comparison groups with a common support. ${ }^{4}$

Matching methods eliminate these last two potential sources of bias by pairing women in managed care counties (treatments) with women in non- managed care counties (controls) that have similar observed attributes. Using observations in the treatment and comparison groups over the region of common support in the distribution of $\mathbf{x}$ eliminates the first source of concern, while the bias due to different distributions of $\mathbf{x}$ between treated and untreated counties within this common support is eliminated by re-weighting the control group observations.

In general, conventional matching methods assume that, conditional on the observed variables $\mathbf{x}$, the counterfactual outcome distribution of the treated units is the same as the observed outcome distribution of the units in the control group. This assumes that there is no selection into treatment on the basis of unobservables. To avoid the necessity of this assumption, Heckman et al (1998b) propose a generalized difference in differences matching estimator that extends conventional matching methods to longitudinal data. By conditioning on fixed-effects, the generalized difference in differences estimator identifies the parameter of interest without ruling out selection into treatment on the basis of time-invariant unobservables.

The objective, then, is to construct a control group by finding controls that have similar observed x's as the treatments. Rosenbaum and Rubin (1983) show that to match treated and untreated units on the basis of $\mathbf{x}$ is equivalent to match them using a balancing score $\mathrm{B}(\mathbf{x})$. The coarsest balancing score is the propensity score which gives the conditional probability of receiving treatment given the pre-treatment values of the vector $\mathbf{x}$, i.e. $P(\mathbf{x})$ $=\operatorname{Pr}\left(M C_{j t}=1 \mid \mathbf{x}\right)$. Then, the method of matching assumes that conditional on $P(\mathbf{x})$, the counterfactual outcome distribution of the treated units is the same as the observed outcome distribution of the controls. This result is very important in practice since it reduces the potential problem of matching on a high dimensional vector $\mathbf{x}$ to matching on a scalar.

\footnotetext{
${ }^{4}$ Heckman et al (1997) suggests that, in practice, the first of these two sources of bias is likely to be the most severe.
} 
We estimate propensity scores using a logit model of the probability that a birth was in a managed care county as a function of the socioeconomic characteristics found in Table 6 . These models are then used to predict the propensity (probability) that a birth is in a managed care county. The logit equation is adjusted by including the interactions between different characteristics to find the best fit possible for each of the different comparison groups. We check that the estimated propensity score does a good job of matching by verifying that the difference in means of the observable characteristics is not significantly different between the treatment and comparison groups within 20 subgroups created based on intervals of the propensity score.

We identify control and treatment observations on a common support as follows. We exclude all control observations whose propensity scores are less than the propensity score of the treatment birth at the first percentile of the treatment propensity score distribution, and exclude all treatment observations whose propensity score is greater than the propensity score of the control observation at the $99^{\text {th }}$ percentile of the control distribution. We then estimate the difference in differences model on the sample with common support which deals with the first form of bias from heterogeneous response. To deal with the second source of bias, we perform separate difference in differences analyses on each the observations within the same decile of the propensity score. However, the estimated effect sizes did not very across deciles and we therefore only report the results for the analysis on the whole overlapping support.

\section{Comparison Groups}

The key to implementing difference in differences analysis is to find valid comparison groups. We have two treatment groups, COHS and TPC, and consider three possible comparison groups that are summarized in Table 2:

1. Comparison 1: Births to mothers covered by Medi-Cal that occurred in counties that did not switch to manage care but stayed on fee-for-service (FFS).

2. Comparison 2: Births to uninsured mothers or "self-pay" mother's that are in the same counties as the TPC or COHS mandates.

3. Comparison 3: Births to mothers covered by Commercial Insurance that occurred in the same counties as the TPC or COHS mandates.

The advantage of comparison group 1, Medi-Cal FFS group, is that both types of patients are enrolled in Medi-Cal and therefore have similar socio-economic characteristics. However, the comparison groups are located in different counties, and these counties tend to be more rural, as they are less populated and have fewer large cities than the treatment counties. Environmental factors such as the availability and quality of medical care might evolve differently over time in these counties implying that the change in this 
comparison group might be a biased estimate of the counterfactual. Comparison groups 2 and 3 are located in the same counties and therefore do not suffer from this bias.

However, self-pay and commercial insurance beneficiaries may look very different from Medi-Cal recipients. While the difference in differences approach controls for differences between the treatment and comparison group that are fixed over time, the self-pay and commercially insured may be subject to different environmental impacts even if located in the same county as the Medi-Cal beneficiaries.

In total there are 1,307,725 treatment observations (Table 3). Approximately 88 percent of these observations are in the TPC Medi-Cal treatment group, leaving 159,204 in the COHS Medi-Cal treatment group. The smallest comparison group is comparison group 2 , the self-pay, with 70,395 observations. There are cases where the mandate became effective during a woman's prenatal care and the woman could have potentially been switched from a fee-for-service system to a managed care plan during her prenatal care or for the delivery. In order not to obscure the impact, we do not use observations from this transition period.

\section{Comparison Group Validity}

A critical assumption is that the change in birth outcomes in the comparison areas is an unbiased estimator of the counterfactual - that is what would have happened to the treatment group if they had not received the intervention. Essentially the change in the outcomes of the comparison group is used to estimate the counterfactual. While we cannot test that the slope of the comparison group is the same as the treatment group in the post intervention period, we can test it in the pre-intervention period. If the slopes are the same in the pre-intervention period, then they are likely to be the same in the postintervention period in the absence of the intervention.

We test the hypothesis that the secular trends between the treatment and comparison groups are the same in the pre-intervention period using the following regression:

$$
Y_{i j t}=\alpha_{j}+\beta_{t} t+\lambda_{t} t T_{j}+\sum_{k} \delta_{k} X_{i t k}+u_{i t}
$$

where $T_{j}=1$ if the county in which zip code $j$ is located will eventually offer managed care to Medi-Cal beneficiaries. If the secular trends are the same then the $\lambda_{t}$ 's will not be significantly different from zero.

We run separate models for both treatment groups with each of the comparison groups using the pre-intervention data. For comparison group 1 we use all Medi-Cal observations from non- managed care counties through the last year before the last treatment county converted. For comparison groups 2 and 3, we only use observations on self-pay and commercially insured patients for the years before the county in which they live converted to managed care (Table 1). We also estimate these models again using only the observations with a common propensity score support. 
The results of the analysis are presented in Tables 4 and 5 where we report the F-statistic and p-value for the joint hypothesis that the year dummies are not statistically different for treatment and comparison counties. For the COHS group we find that the most appropriate counterfactual is Comparison 2, the Self-Pay comparison group. The F-test shows that we cannot reject that the trend in the prenatal care and birth outcome variables between the treatment and comparison groups in the pre-intervention years are the equal.

While the time trends of the Medi-Cal and self-pay groups appear to be the same in the pre-intervention period, there is reason to believe that might of have diverged in the postintervention period even if managed care was not introduced given the dramatic increase in prosperity in California in the second half of the 1990s. Specifically, while the selfpay comparison group may have experienced an increase in incomes during this period the Medi-Cal managed care group's income remained at pre-mandate level (beneficiaries' income must be at 100 percent of the federal poverty line or less to qualify for benefits). Although we attempt to control for differences in income through related variables such as education and age of the mother and father, this potential differential change in income may bias the results. However, if higher incomes lead to better birth outcomes, then any positive difference in differences impacts would represent a lower bound estimate. In this case, the impact of the managed care mandates for the treated would be greater than the potential income effect among the self-pay.

While comparison group 2, the self-pay group in the treatment counties, appears to be a valid control group for the COHS difference in differences analysis, comparison group 1, the Medi-Cal FFS group, is the best of the three choices for the TPC Treatment group. However, this comparison group fails the validity test for four of the six outcome variables at the 10 percent significance level. One reason why comparison group 1, Medi-Cal recipients in non-managed care counties, might also fail to be a good comparison group is that these individuals are located in different counties from the treatment group. It is possible, then, that the secular trends of the treated and untreated might be different over time because the evolution of environmental factors are common to everyone within a county but are different across counties. Since randomization was not used to determine which counties would receive the managed-care mandates, environmental factors may influences the birth outcomes in these counties differently. Indeed, counties with larger and denser populations were on the whole mandated to switch to managed care. The economic expansion in the mid-to-late 1990s for example may have been more prominent in the densely populated managed care counties than in the comparison counties.

Figure 3 demonstrates that environmental factors in the post-mandate period could have influenced birth outcomes. In the pre-mandate period the gap between LBW of the selfpay, comparison 2, in the TPC counties versus the non- managed care (non-MC) counties, comparison 4, is quite small. In the post-mandate period this gap doubles. Remember the self-pay are not part of the managed care mandates, so have not experienced any major health system changes. Changes in LBW in this case must be a result of other factors. Using equation 3 we test statistically that the pre-mandate trends of the birth 
outcomes for the self-pay are the same whether the birth is in a Medi-Cal managed care county (comparison group 2) or in a non- managed care county (comparison group 4). Our suspicions are confirmed. The pre-mandate trends are not significantly different while these trends are significantly different for more than half the variables in the postmandate period,

Given this differential impact of environmental factors in the post-mandate period on the self-pay who live in the treated counties, we worry that although the pre-mandate trends between the TPC treatment and Medi-Cal FFS group are for the most part the same in the pre-mandate period that this will not be the case in the post-mandate period. Therefore, we are reluctant to use difference in differences analysis for the TPC group.

\section{Triple Difference Analysis}

Since the differences in differences approach appears to be problematic for the TPC counties, we instead propose an extension to the approach for these counties.

In this case, we could use a triple difference to control for the differing evolution over time between counties. We could first estimate the difference in the change in birth outcomes of the self-pay group in counties that mandated managed care from the change in birth outcomes of the self-pay group in the counties that did not mandate managed care. Since the self-pay are unaffected by the intervention, this difference in differences measures the change in birth outcomes due to the differing secular trends in the intervention and non-intervention counties. We would then subtract this from the standard difference in differences using the treatment group and comparison groups 1 , Medi-Cal beneficiaries in non-managed care counties. This amounts to subtracting the difference in the secular time trends between comparison group 2 and 4 from the standard difference in differences analysis using comparison group 1 (see Table 2). Similarly, we could instead use the commercial group to control for differences between the county types by using comparison groups 3 and 5 .

In regression form, the triple differences model is:

$$
Y_{i j t}=\alpha_{j}+\beta_{t} t+\gamma M_{i}+\theta M_{i} T_{j}+\lambda_{t} M_{i} t+\eta T_{j} t+\kappa M_{i} T_{j} M C_{j t}+\sum_{k} \delta_{k} X_{i t k}+\varepsilon_{i t}
$$

where $M_{i}=1$ if the birth is covered by Medi-Cal, $T_{j}=1$ if the zip code is in a county that introduced managed care, and $M C_{j t}=1$ if the zip code is in a county that offered managed care to Medi-Cal patients in year $t$. In this case, $\kappa$ is the triple difference estimate of the impact of managed care on Medi-Cal birth outcomes.

The identifying assumption of the triple differences model is that after controlling for the differences in secular trends between the intervention and non-intervention counties, the change in the comparison group is an unbiased estimate of the counterfactual. Again, while this is not directly testable, we can test the hypothesis that the secular trends in the comparison group are the same as in the treatment group in the pre-intervention period after we have adjusted for differences in trends between the intervention and nonintervention counties. 
We implement this test on the pre-intervention observations using the following regression:

$$
Y_{i j t}=\alpha_{j}+\beta_{t} t+\gamma M_{i}+\theta M_{i} T_{i}+\lambda_{t} M_{i} t+\eta_{t} T_{j} t+\kappa_{t} t M_{i} T_{j}+\sum_{k} \delta_{k} X_{i t k}+\varepsilon_{i t}
$$

If the F-test that all the $\kappa_{t}$ 's together is not significantly different from zero, then we cannot reject the hypothesis that the pre-intervention trends in the treatment and comparison groups are the same, adjusting for differences in the trends between the intervention and non-intervention counties.

Our hope then is that the Medi-Cal patients in non-intervention counties (comparison group 1) will be a valid comparison group if we use the self-pay (comparison groups 2 and 4) or the commercial (comparison groups 3 and 5) to adjust for differences in secular trends between intervent ion and non-intervention counties. We estimate equation (5) and report the F-statistics for the joint significance of the $\kappa_{t}$ in Table 5. The results show that if we use the self-pay (comparison groups 2 and 4) to account for differences in spatial trends, that with the exception of premature babies ( $<37$ weeks), we cannot reject that the Medi-Cal beneficiaries in intervention and non-intervention counties similar time trends for all the dependent variables. Variables to control for differences in time trends between medi-cal and non-medical as well as between managed care and non-managed care counties are included equation 4 to account for such differences.

\subsection{The Results}

\section{Summary Statistics}

The means of parent's characteristics during the pre-mandate period are significantly different between all the treatment and comparison groups (Table 7). Comparing the discrepancies in parent's characteristics between the COHS Medi-Cal managed care treatment and self-pay comparison group, comparison group 2, mothers and fathers in the treatment group are approximately 3 to 4 years younger, and have between 2.6 and 2.8 years less education. In the treatment group there are a larger percentage of mothers giving birth that have not finished high school and that are teen mom, as well as a larger proportion of Hispanics than in the self-pay comparison group.

Comparing the TPC Medi-Cal managed care and comparison group 1, the mean age and education levels of the parents differ by less than one year, though there are a larger portion of mothers who have not finished high school, and slightly fewer teen moms in the treatment group. The racial composition between these groups is also different. There are fewer Caucasian parents and more Hispanic parents in the Medi-Cal managed care population than the comparison group, the Medi-Cal FFS population.

The difference in means for many of the birth outcomes, during the pre- and postmandate periods are significantly different between the Medi-Cal managed care counties 
and the comparison groups (Table 7). Many of the differences are actually quite small, yet are significant due to the large sample sizes.

\section{Double and Triple Differences Results}

Given that difference in differences analysis requires a comparison group, we use the propensity score to ensure that the observables of the treatment and comparison groups are in the same range. The impact is reported both before and after this common support is created to examine if it causes any important changes in the results. We also report the results of the impact of the entire post-intervention, as well as, with pooling some years of the together. Specifically, we pool the first two years of the mandates to examine the impact in the initial stages of the managed care mandates, and then pool the rest of the years. We test if the impact in the first two years is different for the impact in the remaining later years.

The results for the COHS treatment group show that managed care has lead to improvements in access to prenatal care but has had almost no impact on birth outcomes (Table 8). There is little difference in the average treatment affect between the outcomes with and without the propensity score common support. We find that the month that a Medi-Cal beneficiary begins prenatal care decreases by about 5 percent, and 6 percent more women started prenatal care in the first trimester. There is a significant $30 \%$ decrease in extremely low birth weight when the common propensity score support is used. There are no other significant reductions in the percent of low birth weight or premature babies.

Furthermore, the managed care mandates had an immediate and growing effect on access to pre-natal care. The month treated woman began prenatal care reduced by almost 4 percent in the first 2 years, but by over 7 percent over the next 4 years of managed care. Likewise, 4 percent more treated woman began prenatal care in the first trimester during the first two years, and this percentage doubled to 8 percent for the remaining 4 years of the program. Interestingly, the reductions in extremely low birth weight occurred during the first two years of the mandates and were not sustained for the following years.

The results on prenatal care access are less profound for the TPC treatment group than for the COHS, but we find important reductions in both the number of low birth weight and premature babies for this group (Table 9). This time there are differences in both the impacts and the significance levels if a common propensity score support is used. Without the propensity score common support, there is a significant reduction in the month prenatal care began of almost 1 percent and a similar increase in Medi-Cal mom starting prenatal care in the first trimester. With the common propensity score support the impacts are the same but they are no longer significant. There is also a more than 8 and 7 percent decline in the in incidence of premature and low birth weight babies for those who have a common propensity score.

Turning to the pooled impacts, we find the reductions in the month prenatal care begins, the percent of woman starting prenatal care in the first trimester, and the incidence of 
premature babies are realized in the first two years of the program. During the remaining years of the program, these reductions however are not sustained for the two prenatal care access indicators but are for the incidence of premature babies. While there is not a significant reduction in LBW babies in the initial years of the mandates, there is a 9 to 11 percent reduction in number of low birth weight babies in the later years of the mandates.

\subsection{Discussion}

In this paper we investigated whether mandating making managed care available to MediCal beneficiaries improved access to prenatal care and birth outcomes. We compared two competing models: COHS, which offered a single non-commerical, managed care option and TPC, which offered both a non-commercial and commercial option.

Our results suggest that the Medi-Cal managed care mandates have significantly improved access to care as measured by the month prenatal care began and by whether prenatal care began in the first trimester in the COHS model but did not in the TPC model. The availability of COHS managed care led to an approximately 5 percent reduction in both the month that prenatal care began and the percent of woman who begin prenatal care in the first trimester. We observed these improvements in access beginning in the first of year of COHS implementation and the effects grew over time.

In contrast, we found that birth outcomes measured by low-birth weight and prematurely significantly improved in the TPC model, but not in the COHS model. Specifically, we found that there was 9 percent decrease in LBW and a similar reduction in the percentage of premature babies in TPC counties. While the incidence of premature babies decreased in the first year of TPC implementation, it took at least two years of program implementation before we observed significant reductions in number of low-birth babies. These results suggest that early initiation of care may not by itself lead to better birth outcomes and there are other aspects of prenatal care that may matter more.

The TPC managed care model was able to improve health outcomes of newborns in the absence of changes in access to prenatal care. The major difference between the TPC and COHS models is the availability of a second managed care option provided by commercial plans. Indeed, the presence of commercial managed care plans may have been a driving force behind these results. The commercial groups effectively mainstream Medi-Cal beneficiaries into care equivalent to mothers with higher incomes. Access measured by time of initiation of prenatal care may not have increased for the Medi-Cal beneficiaries, but the quality of commercial services may be better than what they were receiving before from the traditional Medi-Cal network of providers. Moreover, the commercial option in the TPC model may have put competitive pressure on the noncommercial managed care option to provide better quality of care. Our results suggest that providing a commercial managed option is key to making managed care work for poor populations. 
The fact that we demonstrate that the TPC managed care had positive health benefits is important given that there do not appear to be any cost savings for Medi-Cal from managed care (Duggan 2002). Despite the lack of cost savings, our results provide a rationale for Medicaid turning to Managed Care. Medicaid programs can make healthier babies by providing commercial managed care options that main stream beneficiaries. 


\section{References}

A Profile of Medicaid: Chartbook2000, Health Care Financing Administration (HCFA), Washington D.C.: US Department of Health and Human Services, 2000.

County Data, (Sept. 18 2002), Medi-Cal Policy Institute web site, http://www.medical.org.

Medi-Cal Managed Care, Medi-Cal Facts 1, Medi-Cal Policy Institute, Oakland, CA., 1998.

Medicaid and Managed Care, Kaiser Commission on Medicaid and the Uninsured, Washington, DC., 1999.

Medi-Cal Facts Number 8, Medi-Cal Policy Institute, Oakland, CA., March 2000.

Speaking Out... What Beneficiaries Say About the Medi-Cal Program, Medi-Cal Policy Institute, Oakland, CA., 2000.

Understanding Medi-Cal: The Basics, Medi-Cal Policy Institute, Oakland, CA., 1998.

Billings, J., G.M. Anderson, L.S. Newman, "Recent Findings on Preventable Hospitalizations," Health Affairs, 1996, 15(3), 239-249.

Bindman, A.B., K.Grumbach, D. Osmond, M. Komaromy, K. Vranizan, N. Lurie, J. Billings, A. Stewart, "Preventable Hospitalizations and Access to Care," JAMA, 1995, 274(4), 305-311.

Carey, T.S., K. Weis, C. Homer, "Prepaid versus Traditional Medicaid Plans: Lack of Effect on Pregnancy Outcomes and Prenatal Care," Health Services Research 1991, 26(2), 165-181.

Chay, K., D. Almond, D. Lee, "Does Low Birth Weight Matter? Evidence for the U.S. Population of Twin Birth," Mimeo, Department of Economics, University of California at Berkeley, August 2002.

Chiu, H., "Health Insurance and the Welfare of Health Consumers," The Journal of Public Economics, 1997, 64(1),125-133.

Coburn A., S. Long, and M. Marquis, "Effects of Changing Medicaid Fees on Physician Participation and Enrollee Access," Inquiry, Fall 1999, 36, 265-279.

Currie, J. and J. Gruber, "Health Insurance Eligibility, Utilization of Medical Care, and Child Health," Journal of Political Economics, 1996, 111(2), 431-466. 
Cutler, D. and L. Sheiner, Managed Care and the Growth of Medical Expenditures, National Bureau of Economic Research Working Paper 6140, 1997.

Cutler, D., M. McClellan, J. Newhouse, "How Does Managed Care Do It?" Rand Journal of Economics, 2000, 31, 526-548.

Deal, L.W. and P.H. Shiono, "Medicaid Managed Care and Children: An Overview," The Future of Children, 1998, 8(2), 93-104.

Donohue, P.K., "Health-Related Quality of Life of Preterm Children and Their Caregivers, Ment Retard Dev Disabil Res Rev, 2002, 8(4):293-7.

Duggan, M., "Does Contracting Out Increase the Efficiency of Government Programs? Evidence from Medicaid HMOs," NBER working paper 9091, 2002.

Elgen I. Sommerfelt K., Markestad T. "Population Based, Controlled Study of Behavioural Problems and Psychiatric Disorders in Low Birth Weight Children at 11 Years of Age", Arch Dis Child Fetal Neonatal Ed, 2002, 87(2):28-32

Feldstein, P.J., Health Care Economics, Delmar: Boston, 1999.

Gavin, N.I., M.C. Farrelly, J.B. Simpson, "Children's Use of Primary and Preventive Care Under Medicaid Managed Care," Health Care Financing Review, 1998, 19(4), 45-68.

Goldfarb, N.I., A.L. Hillman, J.M. Eisenberg, M.A. Kelley, A.V. Cohen, M. Dellheim, "Impact of a Mandatory Medicaid Case Management Program on Prenatal Care and Birth Outcomes: A Retrospective Analysis," Medical Care, 1991, 29(1), 6471.

Griffin, J.E., J.W. Hogan, J.S. Buechner, T.M. Leddy, “The Effect of a Medicaid Managed Care Program on the Adequacy of Prenatal Care Utilization in Rhode Island," American Journal of Public Health 1999, 89(4), 497-501.

Kaestner, R., L. Dubay, G. Kenney, "Medicaid Managed Care and Infant Health: A National Evaluation," NBER working paper 8936, 2002.

Kreiger, J.W., F.A. Connell, J.P. LoGerfo, "Medicaid Prenatal Care. A Comparison of Use and Outcomes in Fee-for-Services and Managed Care," American Journal of Public Health, 1992, 82(2), 185-190.

Kotch, J.B. and R. Barber-Madden, "Chapter 15: The Case for Universal Maternity Care," in A Pound of Prevention: The Case for University Maternity Care in the US, American Public Health Association, Washington D.C., 1992. 
Kotelchuck, M., "An Evaluation of the Kessner Adequacy of Prenatal Care Index and a Proposed Adequacy of Prenatal Care Index," American Journal of Public Health, 1994, 84(9), 1414-1420.

Levinson, A. and F. Ullman, "Medicaid Managed Care and Infant Health," Journal of Health Economics, 1998, 17(3), 351-368.

Leibowitz, A, J.L Buchanan, J. Mann, "A Randomized Comparisonled Trial to Evaluate the Effectiveness of a Medicaid HMO," Journal of Health Economics, 1992, 11, 235-257.

Luft, H.A. Health Maintenance Organizations: Dimensions of Performance, John Wiley and Sons, New York, 1981

Manning, W.G, H. Leibowitz, G.H Goldberg, W.H. Rogers, and J. Newhouse, "A Controlled Trial of the Effect of a Prepaid Practise on the Use of Service" The New England Journal of Medicine, 1984, 310(23):1505-1510.

Mattison, D.R, K. Damus, E.Fiore, J.Petrini, C. Atler, “Preterm Delivery : A Public Health Perspective," Paediatric and Perinatal Epidemiology, 2001, 15 (Suppl. 2), 7-16.

Mauldon J., A. Leibowitz, J.L. Buchanan, C. Damberge, K.A. McGuigan, "Rationing or Rationalizing Children's Medical Care: Comparison of a Medicaid HMO with Fee-for-Service Care," American Journal of Public Health 84(6): 899-904.

McCall, N., J. Korb, P. Turner, A. Peterson, The Medi-Cal Managed Care Market 19961998, prepared for the Medi-Cal Policy Institute by Laguna Research Associates, 2000.

Menges J., C. Park, J. Babcock, C. Chimento, R. Haught, and S. Ho, "Comparin Physician and Dentist Fees Among Medicaid Programs," Prepared for the MediCal Policy Institute by The Lewin Group, June 2001.

Miller, R.H. and H.S Luft, "Managed-Care Plan Performance Since 1980: A Literature Analysis," JAMA, 271:1512-1519.

Millman, M., Access to Health Care in America, National Academy Press, Washington, D.C., 1993.

Oleske, D.M., M.L. Branca, J.B. Schmidt, F. Ferguson, E.S. Linn, "A Comparison of Capitated and Fee-for-Service Medicaid Reimbursement Methods on Pregnancy Outcomes," Health Services Research, 1998, 33(1), 55-73. 
Paneth, N.S., "The Problem of Low Birth Weight," The Future of Children, 1995, 5(1), 19-34.

Ray, WA, J. Gigante, E.F. Mitchel, G.B. Hickson, "Perinatal Outcomes Following Implementation of TennCare" JAMA, 1998, 279(4), 314-316.

Rosenbaum, P and D. Rubin, "The Central Role of the Propensity Score in Observational Studies of Causal Effect," Biometrika, 1983, 70(1), 41-55.

Rosenbaum, P. and D. Rubin, "Reducing Bias in Observational Studies Using Subclassification on the Propensity Scores," The Journal of the American Statistical Association, 1984, 79, 516-524.

Schauffler, H.H. and E.R. Brown, The State of Health Insurance in California, 1999, Regents of the University of California, Berkeley, CA., 2000.

Strauss, R.S. "Adult Functional Outcome of These Born Small for Gestational Age: Twenty-six-year Follow Up on the 1970 British Birth Cohort", JAMA, 2000,283(5):625-32.

Szilagyi P.G., "Managed Care for Children: Effect on Access to Care and Utilization of Health Services," The Future of Children,

Taylor H.G, N. Klein, N.M Minish M. Hack, Middle-School-Age Outcomes in Children with Very Low Birthweight, Child Development, 2000,71(6):1495-511. 
Figure 1: Medicaid Managed Care (MMC) Penetration Rates, 1991-2002

Enrolled in MMC in US Enrolled in MMC in California

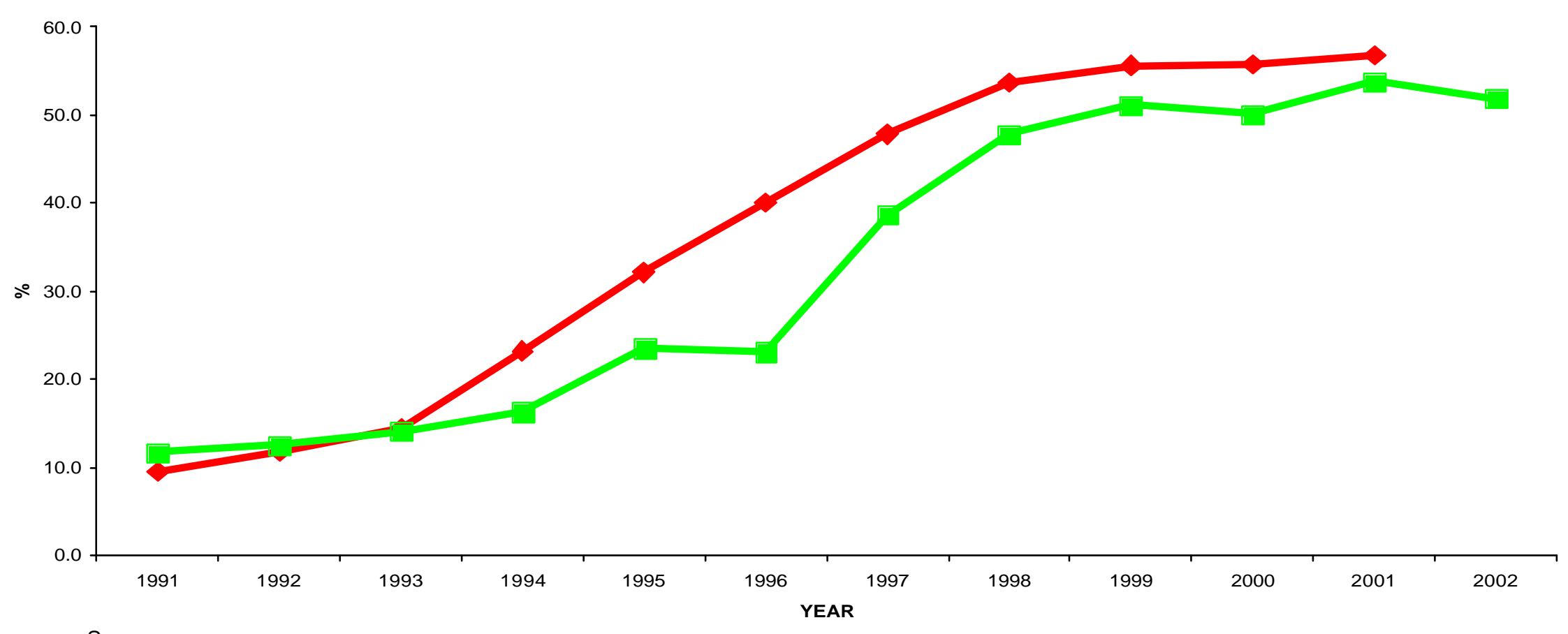

Sources:

1. Medicaid Population and Enrollment data from: Medicaid Managed-Care Enrollment Reports (1995-2001), Centers for Medicare and

Medicaid Service.

2. Delivery Data: Provided by California Department of Health Services.

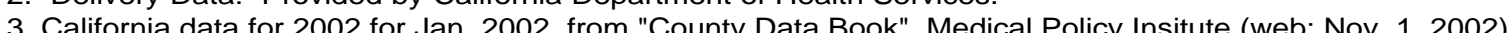




\section{Figure 2: California's Medicaid Managed Care Experiment}

( 22 out of 58 counties in managed care)

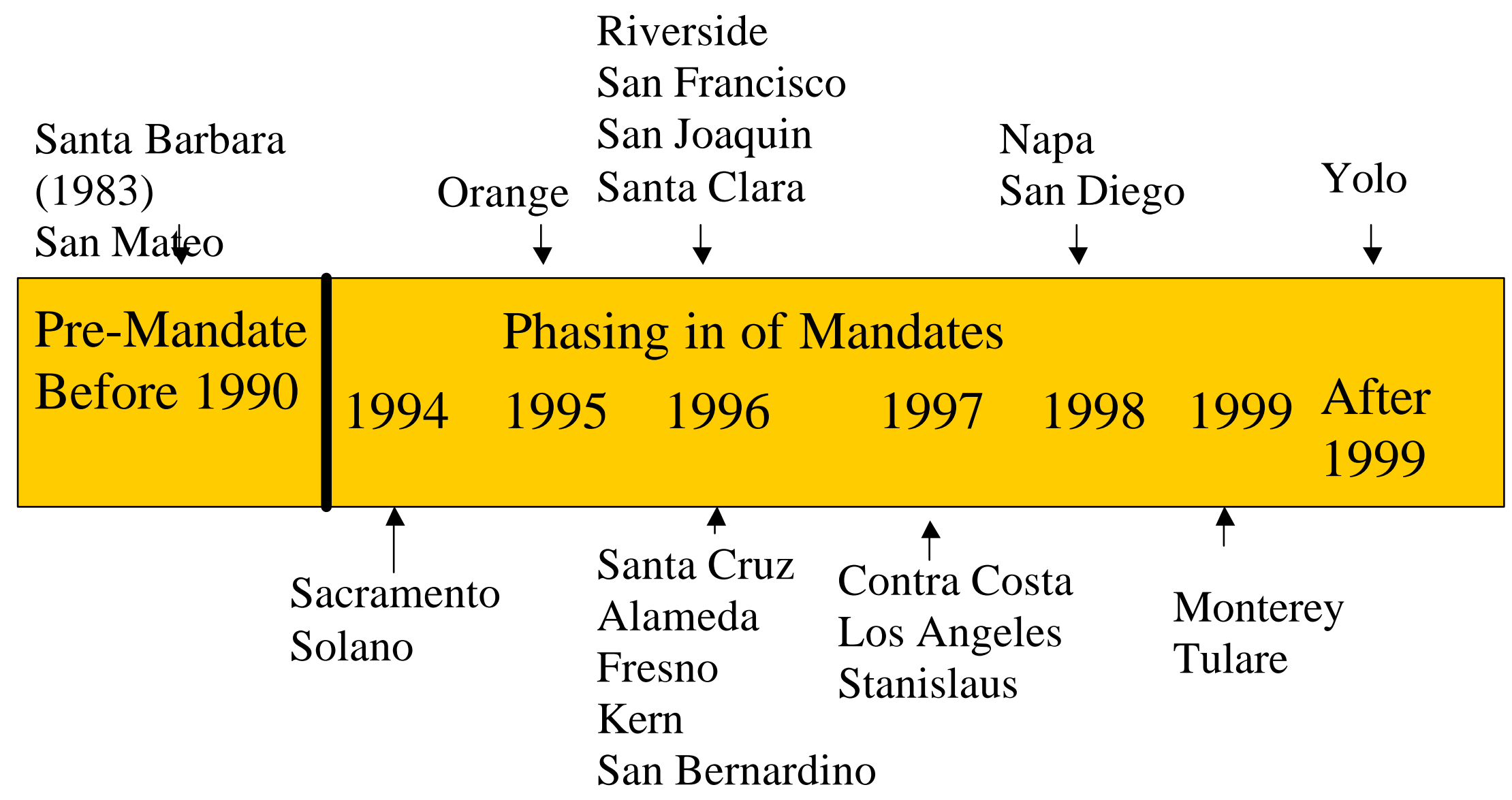


Figure 3: Trend in the Mean of LBW for TPC Treatment and Medi-Cal FFS Control Group using Self-Pay to Adjust for Secular Trends

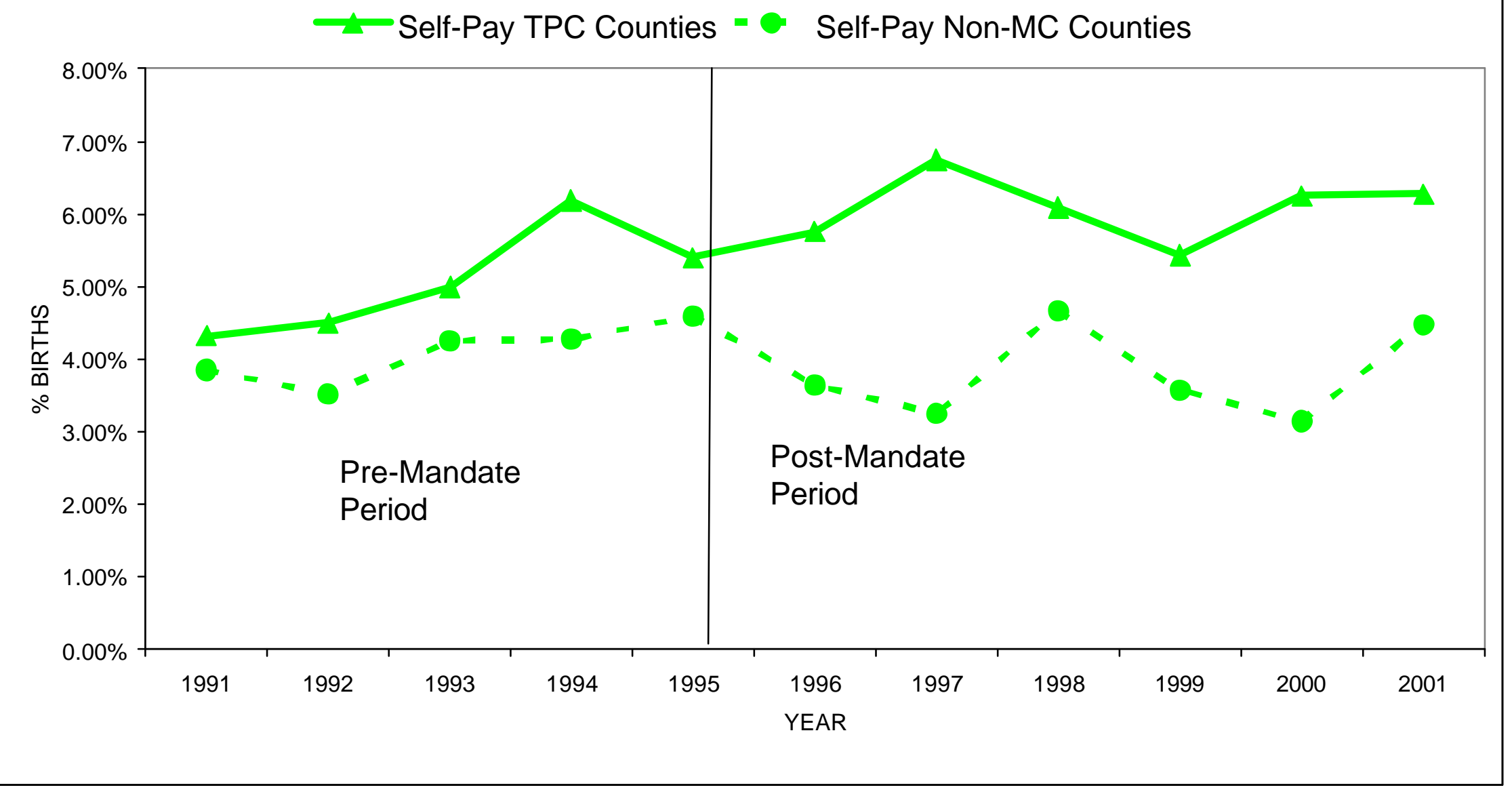


Table 1: Medi-Cal Managed-Care Plan Types and Beneficiary Information by County

\begin{tabular}{|c|c|c|c|c|c|c|}
\hline \multirow[t]{2}{*}{ County } & \multirow[t]{2}{*}{$\begin{array}{l}\text { Plan } \\
\text { Type }\end{array}$} & \multirow{2}{*}{$\begin{array}{l}\text { Date } \\
\text { Managed } \\
\text { Care } \\
\text { Began }\end{array}$} & \multirow{2}{*}{$\begin{array}{c}\text { Total } \\
\text { Population } \\
(2001)\end{array}$} & \multicolumn{2}{|c|}{$\begin{array}{c}\text { Number of Medi-Cal } \\
\text { Beneficiaries as of } 01 / 02\end{array}$} & \multirow{2}{*}{$\begin{array}{c}\% \text { of County } \\
\text { Medi-Cal } \\
\text { Beneficiaries in } \\
\text { TPC, COHS Plans } \\
(\%)\end{array}$} \\
\hline & & & & Total & $\begin{array}{c}\text { in TPC, } \\
\text { coHS Plans }\end{array}$ & \\
\hline California & & & & $5,840,000$ & $2,642,865$ & $45 \%$ \\
\hline \multicolumn{7}{|c|}{ By Type of Managed-Care Plan } \\
\hline \multirow{2}{*}{\multicolumn{2}{|c|}{ Total in COHS counties }} & & & $4,097,040$ & $2,176,136$ & \\
\hline & & & $5,427,796$ & 575,361 & 466,729 & 81 \\
\hline \multicolumn{7}{|l|}{ By County } \\
\hline Monterey & $\mathrm{COHS}$ & Oct-99 & 409,511 & 63,953 & 48,190 & 75 \\
\hline Napa & COHS & Mar-98 & 129,130 & 10,492 & 8,345 & 80 \\
\hline Orange & $\mathrm{COHS}$ & Oct-95 & $2,872,632$ & 301,928 & 241,333 & 80 \\
\hline Santa Cruz & $\mathrm{COHS}$ & Jan-96 & 264,525 & 27,248 & 23,032 & 85 \\
\hline Solano & $\mathrm{COHS}$ & May-94 & 408,095 & 45,106 & 41,140 & 91 \\
\hline San Mateo & $\mathrm{COHS}$ & Dec-87 & 759,313 & 47,741 & 38,659 & 81 \\
\hline Santa Barbara & $\mathrm{COHS}$ & Sep-83 & 417,331 & 54,486 & 44,862 & 82 \\
\hline Yolo & $\mathrm{COHS}$ & May-01 & 167,259 & 24,407 & 21,168 & 87 \\
\hline Alameda & TPC & Jan-96 & $1,492,004$ & 186,533 & 96,037 & 51 \\
\hline Contra Costa & TPC & Feb-97 & 942,662 & 89,468 & 45,667 & 51 \\
\hline Fresno & TPC & Nov-96 & 825,365 & 235,991 & 149,999 & 64 \\
\hline Kern & TPC & Jul-96 & 694,749 & 162,118 & 94,880 & 59 \\
\hline Los Angeles & TPC & Apr-97 & $9,925,413$ & $2,271,306$ & $1,234,727$ & 54 \\
\hline Riverside & TPC & Sep-96 & $1,626,134$ & 226,370 & 121,642 & 54 \\
\hline San Bernardino & TPC & Sep-96 & $1,771,707$ & 314,532 & 166,853 & 53 \\
\hline San Francisco & TPC & Jul-96 & 794,342 & 113,556 & 41,217 & 36 \\
\hline San Joaquin & TPC & Feb-96 & 593,538 & 119,137 & 68,708 & 58 \\
\hline Santa Clara & TPC & Oct-96 & $1,795,132$ & 165,391 & 69,934 & 42 \\
\hline Stanislaus & TPC & Oct-97 & 472,096 & 97,228 & 26,365 & 27 \\
\hline Tulare & TPC & Feb-99 & 388,730 & 115,410 & 60,107 & 52 \\
\hline
\end{tabular}

Sources: Medi-Cal Policy Institute County Data; McCall et al.; Schauffler 2000.

Notes:

1/ Two-Plan Counties (TPC), County Organized Health Systems (COHS), represent the two main managed-care plan types in California.

2/ Sacramento and San Diego have Geographic Managed Care, we do not study this type of managed care program.

3/ The following counties still use feefor-service for the Medi-Cal population: Alpine, Amador, Butte, Calaveras, Colusa, Del Norte, El Dorado, Glenn, Humboldt, Imperial, Inyo, Kings, Lake, Lassen, Madera, Marin, Mariposa, Mendocino, Merced, Modoc, Mono, Nevada, Placer, Plumas, San Benito,

San Luis Obispo, Shasta, Sierra, Siskiyou, Sonoma, Sutter, Tehama, Trinity, Tuolumne, Ventura, Yuba. 
Table 2: Potential Treatment and Comparison Groups

\begin{tabular}{|l|c|c|}
\hline Insurance Type & $\begin{array}{c}\text { Medi-Cal Managed Care } \\
\text { Counties }\end{array}$ & Medi-Cal FFS Counties \\
\hline Medi-Cal & Treatment (COHS or TPC) & Comparison 1 \\
\hline Self-Pay & Comparison 2 & Comparison 4 \\
\hdashline Commercial & Comparison 3 & Comparison 5 \\
\hline
\end{tabular}


Table 3: Number of Births

\begin{tabular}{|c|c|c|c|c|c|}
\hline Group & $\begin{array}{c}\text { Pre- } \\
\text { Mandate }\end{array}$ & $\begin{array}{c}\text { Post- } \\
\text { Mandate }\end{array}$ & $\begin{array}{c}\text { Total of } \\
\text { Pre- and } \\
\text { Post- } \\
\text { Mandate }\end{array}$ & $\begin{array}{l}\text { Transition } \\
\text { Period /4 }\end{array}$ & Total \\
\hline Medi-Cal TPC Treatment & 639,172 & 408,234 & $1,047,406$ & 101,115 & $1,148,521$ \\
\hline Medi-Cal COHS Treatment & 63,091 & 81,350 & 144,441 & 14,763 & 159,204 \\
\hline Medi-Cal FFS Control for TPC /1 & 307,580 & 293,299 & 600,879 & 0 & 552,047 \\
\hline $\begin{array}{l}\text { Medi-Cal FFS Control for COHS } \\
/ 2\end{array}$ & 452,118 & 393,085 & 845,203 & 0 & 552,047 \\
\hline TPC Self-Pay Control & 31,928 & 20,485 & 52,413 & 5,157 & 57,570 \\
\hline COHS Self-Pay Control & 4,837 & 6,941 & 11,778 & 1,047 & 12,825 \\
\hline TPC Commercial Control & 609,345 & 537,703 & $1,147,048$ & 114,500 & $1,261,548$ \\
\hline COHS Commercial Control & 87,771 & 151,569 & 239,340 & 23,540 & 262,880 \\
\hline
\end{tabular}

Notes:

1/ These counties have no official pre or post mandate period. We use years that cover the entire pre- or post mandate period of the treatment group. Pre-mandate period is 1991-1996 and post-mandate period is 1996-2001.

2/ These counties have no official pre or post mandate period, We use years that cover the entire pre- or post mandate period of the treatment group. Pre-mandate period is 1991-1999 and post-mandate period is 1994-2001.

3/ Two-Plan Counties (TPC), County Organized Health Systems (COHS), are the tw o main managed-care plan types in California.

4/ Transition period includes all births where managed care started in a county during the pregnancy. 
Table 4

Test for Secular Trends in Pre-Intervention Years for COHS Treatment Group

Without Propensity Score Common Support (NO PS) and with Propensity Score Common Support (PS)

\begin{tabular}{|c|c|c|c|c|c|c|c|c|c|c|c|c|}
\hline & \multicolumn{2}{|c|}{ Month Start } & \multicolumn{2}{|c|}{ First Trimester } & \multicolumn{2}{|c|}{$\begin{array}{c}\text { LBW } \\
(<2500 \mathrm{~g})\end{array}$} & \multicolumn{2}{|c|}{$\begin{array}{c}\text { xLBW } \\
(<1000 \mathrm{~g})\end{array}$} & \multicolumn{2}{|c|}{$\begin{array}{l}\text { Premature } \\
\text { (37 wks) }\end{array}$} & \multicolumn{2}{|c|}{$\begin{array}{l}\text { Premature } \\
\text { (<33 wks) }\end{array}$} \\
\hline & NO PS & PS & NO PS & PS & NO PS & PS & NO PS & PS & NO PS & PS & NO PS & PS \\
\hline \multicolumn{13}{|c|}{ COHS Treatment and Comparison 1} \\
\hline Observations & 303,750 & 229,089 & 303,750 & 229,089 & 303,750 & 229,089 & 303,750 & 229,089 & 303,750 & 229,089 & 303,750 & 229,089 \\
\hline F-value $/ 1$ & 288.13 & 92.54 & 198.76 & 60.78 & 0.52 & 2.47 & 0.01 & 0.03 & 1.38 & 0.23 & 0.27 & 0 \\
\hline $\mathrm{P}$-value /2 & 0 & 0 & 0 & 0 & 0.47 & 0.12 & 0.94 & 0.87 & 0.24 & 0.63 & 0.6 & 0.97 \\
\hline \multicolumn{13}{|c|}{ COHS Treatment and Comparison 2} \\
\hline Observations & 140,996 & 126,143 & 140,996 & 126,143 & 140,996 & 126,143 & 140,996 & 126,143 & 140,996 & 126,143 & 140,996 & 126,143 \\
\hline F-value $/ 1$ & 1.4 & 2.83 & 0.49 & 1.45 & 0.37 & 0.02 & 2.07 & 1.36 & 1.45 & 1.94 & 1.41 & 1.58 \\
\hline P-value /2 & 0.24 & 0.09 & 0.48 & 0.23 & 0.54 & 0.88 & 0.15 & 0.24 & 0.23 & 0.16 & 0.24 & 0.21 \\
\hline \multicolumn{13}{|c|}{ COHS Treatment and Comparison 3} \\
\hline Observations & 303,461 & 228,003 & 303,461 & 228,003 & 303,461 & 228,003 & 303,461 & 228,003 & 303,461 & 228,003 & 303,461 & 228,003 \\
\hline F-value $/ 1$ & 1849.17 & 1896.87 & 1345.91 & 1361.33 & 10.24 & 7.17 & 5.2 & 2.9 & 16.17 & 17.11 & 7.61 & 6.8 \\
\hline $\mathrm{P}$-value /2 & 0 & 0 & 0 & 0 & 0 & 0.01 & 0.02 & 0.09 & 0 & 0 & 0.01 & 0.01 \\
\hline
\end{tabular}

Notes:

11 The $\mathrm{F}$ value from the F-test which tests jointly if coefficents on the year dummies interacted with the mandate dummy are significant.

/2 The p-value from the F-test. 
Table 5

Test for Secular Trends in Pre-Intervention Years for TPC Groups

Without Propensity Score Common Support (NO PS) and with Propensity Score Common Support (PS)

\begin{tabular}{|c|c|c|c|c|c|c|c|c|c|c|c|c|}
\hline & \multicolumn{2}{|c|}{ Month Start } & \multicolumn{2}{|c|}{ First Trimester } & \multirow{2}{*}{\multicolumn{2}{|c|}{$\begin{array}{c}\text { LBW } \\
(<2500 \mathrm{~g})\end{array}$}} & \multirow{2}{*}{\multicolumn{2}{|c|}{$\begin{array}{c}\text { XLBW } \\
(<1000 \mathrm{~g})\end{array}$}} & \multirow{2}{*}{\multicolumn{2}{|c|}{$\begin{array}{c}\text { Premature } \\
\text { (37 wks) }\end{array}$}} & \multirow{2}{*}{\multicolumn{2}{|c|}{$\begin{array}{l}\text { Very Premature } \\
\text { (<33 wks) }\end{array}$}} \\
\hline & NO PS & PS & NO PS & PS & & & & & & & & \\
\hline \multicolumn{13}{|c|}{ TPC Treatment and Comparison 1} \\
\hline F-value $/ 1$ & 3.07 & 64.67 & 4.68 & 48.32 & 3.4 & 6.72 & 0.57 & 1.01 & 6.69 & 4.09 & 0.02 & 0.58 \\
\hline Pvalue /2 & 0.08 & 0 & 0.03 & 0 & 0.07 & 0.01 & 0.45 & 0.31 & 0.01 & 0.04 & 0.89 & 0.45 \\
\hline \multicolumn{13}{|c|}{ TPC Treatment and Comparison 2} \\
\hline Observations & 1067866 & 1003610 & 1067866 & 1003610 & 1067866 & 1003610 & 1067866 & 1003610 & 1067866 & 1003610 & 1067866 & 1003610 \\
\hline Pvalue /2 & 0 & 0 & 0 & 0 & 0.02 & 0 & 0 & 0 & 0 & 0 & 0 & 0 \\
\hline \multicolumn{13}{|c|}{ TPC Treatment and Comparison 3} \\
\hline Observations & 2057025 & 1620103 & 2057025 & 1620103 & 2057025 & 1620103 & 2057025 & 1620103 & 2057025 & 1620103 & 2057025 & 1620103 \\
\hline F-value $/ 1$ & 13890.8 & 13251.1 & 12071.1 & 11480.1 & 516.8 & 471.99 & 17.8 & 13.87 & 395.86 & 403.3 & 177.6 & 155.31 \\
\hline Pvalue /2 & 0 & 0 & 0 & 0 & 0 & 0 & 0 & 0 & 0 & 0 & 0 & 0 \\
\hline \multicolumn{13}{|c|}{ Comparison 2 (TPC counties) and Comparison 4 Pre-int } \\
\hline Obse & 72026 & 47528 & 72026 & 47528 & 72026 & 47528 & 72026 & 47528 & 72026 & 47528 & 72026 & 47528 \\
\hline F-value $/ 1$ & 12.57 & 4.93 & 3.53 & 0.62 & 1.88 & 0.01 & 3.26 & 3.49 & 7.32 & 4.42 & 2.64 & 0.43 \\
\hline Pvalue /2 & 0 & 0.03 & 0.06 & 0.43 & 0.17 & 0.94 & 0.07 & 0.06 & 0.01 & 0.04 & 0.1 & 0.51 \\
\hline \multicolumn{13}{|c|}{ Triple Difference: TPC Treatment and Comparison 1 with Comparison 2 and 4} \\
\hline Observations & 1118005 & 607733 & 1118005 & 607733 & 1118005 & 607733 & 1118005 & 607733 & 1118005 & 607733 & 1118005 & 607733 \\
\hline F-value $/ 1$ & 0.67 & 0 & 0.32 & 0.02 & 0.63 & 0.15 & 1.34 & 0.37 & 3.31 & 5.29 & 0.94 & 0.45 \\
\hline Pvalue /2 & 0.41 & 0.97 & 0.57 & 0.9 & 0.43 & 0.69 & 0.25 & 0.54 & 0.07 & 0.02 & 0.33 & 0.5 \\
\hline \multicolumn{13}{|c|}{ Triple Difference: TPC Treatment and Comparison 1 with Comparison 3 and 5} \\
\hline Observations & 2190987 & 1361162 & 2190987 & 1361162 & 2190987 & 1361162 & 2190987 & 1361162 & 2190987 & 1361162 & 2190987 & 1361162 \\
\hline F-value $/ 1$ & 47.52 & 105.53 & 38.9 & 83.07 & 1.9 & 4.59 & 2.29 & 4.96 & 2.52 & 4.24 & 2.11 & 2.76 \\
\hline Pvalue /2 & 0 & 0 & 0 & 0 & 0.17 & 0.03 & 0.13 & 0.03 & 0.11 & 0.04 & 0.15 & 0.1 \\
\hline
\end{tabular}

Notes:
11 The $F$ value from the F-test which tests jointly if coefficents on the year dummies interacted with the mandate dummy are significant.

/2 The p-value from the F-test. 
Table 6

Means of Parent Characteristics

\begin{tabular}{|c|c|c|c|c|}
\hline Parent's Characteristic & Treatment & $\begin{array}{r}\text { Control } \\
\text { Group }\end{array}$ & $\begin{array}{r}\text { Difference } \\
\text { in Means }\end{array}$ & Significance \\
\hline \multicolumn{5}{|c|}{ COHS Treatment and Comparison 2 (self-pay) } \\
\hline Age of father & 28.1 & 32.2 & -4.2 & $* \star *$ \\
\hline Education of father & 9.6 & 12.4 & -2.8 & *** \\
\hline Age of mother & 25.1 & 28.5 & -3.4 & $* * *$ \\
\hline Education of mother & 9.5 & 12.1 & -2.6 & $\star \star \star *$ \\
\hline Mother's age $<18=1$ & $6.4 \%$ & $2.6 \%$ & $3.80 \%$ & $* * *$ \\
\hline Mother's Age $>35=1$ & $6.0 \%$ & $12.6 \%$ & $-6.66 \%$ & $* * *$ \\
\hline Mother had no highschool $=1$ & $32.5 \%$ & $14.8 \%$ & $17.67 \%$ & $* * *$ \\
\hline Mother had some highschool $=1$ & $29.6 \%$ & $14.3 \%$ & $15.29 \%$ & $* * *$ \\
\hline Mother had some college $=1$ & $8.8 \%$ & $21.0 \%$ & $-12.20 \%$ & $* \star *$ \\
\hline Mother finished college $=1$ & $2.6 \%$ & $21.8 \%$ & $-19.13 \%$ & $* \star *$ \\
\hline No father present $=1$ & $4.3 \%$ & $2.5 \%$ & $1.75 \%$ & $* \star *$ \\
\hline Parents both White $=1$ & $9.3 \%$ & $34.2 \%$ & $-24.93 \%$ & $* * *$ \\
\hline Parents both Black =1 & $1.9 \%$ & $0.6 \%$ & $1.32 \%$ & $* * *$ \\
\hline Parents both Hispanic $=1$ & $73.4 \%$ & $38.0 \%$ & $35.48 \%$ & $\star \star \star *$ \\
\hline Parents both East Asian $=1$ & $4.9 \%$ & $14.4 \%$ & $-9.49 \%$ & $* * *$ \\
\hline Parents both Southern Asian $=1$ & $0.2 \%$ & $0.7 \%$ & $-0.47 \%$ & $* * *$ \\
\hline Mixed Parents & $9.5 \%$ & $10.8 \%$ & $-1.29 \%$ & $* \star *$ \\
\hline \multicolumn{5}{|c|}{ TPC Treatment and Comparison 1 (Medi-Cal FFS) } \\
\hline Age of father & 28.2 & 27.7 & 0.4 & $* * *$ \\
\hline Education of father & 10.1 & 10.2 & -0.1 & $* \star \star$ \\
\hline Age of mother & 25.1 & 24.6 & 0.5 & $* \star *$ \\
\hline Education of mother & 10.0 & 10.3 & -0.3 & 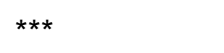 \\
\hline Mother's age $<18=1$ & $7.5 \%$ & $8.0 \%$ & 0.0 & $\star \star \star *$ \\
\hline Mother's Age $>35=1$ & $6.3 \%$ & $5.8 \%$ & $0.54 \%$ & $* * *$ \\
\hline Mother had no highschool $=1$ & $25.6 \%$ & $22.1 \%$ & $3.55 \%$ & $* * *$ \\
\hline Mother had some highschool $=1$ & $31.3 \%$ & $27.8 \%$ & $3.54 \%$ & $* * *$ \\
\hline Mother had some college $=1$ & $10.1 \%$ & $12.6 \%$ & $-2.52 \%$ & $\star \star \star *$ \\
\hline Mother finished college $=1$ & $2.5 \%$ & $2.6 \%$ & $-0.09 \%$ & $* \star \star *$ \\
\hline No father present $=1$ & $5.4 \%$ & $5.1 \%$ & $0.31 \%$ & $* \star *$ \\
\hline Parents both White $=1$ & $8.5 \%$ & $25.8 \%$ & $-17.28 \%$ & $* * *$ \\
\hline Parents both Black $=1$ & $8.2 \%$ & $1.5 \%$ & $6.76 \%$ & $* \star \star$ \\
\hline Parents both Hispanic $=1$ & $67.0 \%$ & $52.0 \%$ & $14.95 \%$ & $* * *$ \\
\hline Parents both East Asian $=1$ & $3.8 \%$ & $3.2 \%$ & $0.63 \%$ & $* * *$ \\
\hline Parents both Southern Asian $=1$ & $0.3 \%$ & $0.4 \%$ & $-0.13 \%$ & $* * *$ \\
\hline Mixed Parents & $11.2 \%$ & $16.2 \%$ & $-4.99 \%$ & $* * *$ \\
\hline
\end{tabular}

$1 /{ }^{*}$ significant at $10 \% ;{ }^{* *}$ significant at $5 \% ;{ }^{* * *}$ significant at $1 \%$

2/ Two-Plan Counties (TPC), County Organized Health Systems (COHS) represent the two main managed-care plan types in California.

3/ FFS = fee-for-service 
Table 7

Summary Statistics of Birth Outcomes

\begin{tabular}{|c|c|c|c|c|c|c|c|c|c|}
\hline \multirow[t]{2}{*}{ Birth Outcomes } & \multicolumn{4}{|c|}{ Pre-Mandate Period } & \multicolumn{4}{|c|}{ Post-Mandate Period } & \multirow{2}{*}{$\begin{array}{r}\text { Double } \\
\text { Diff. }\end{array}$} \\
\hline & $\begin{array}{l}\text { Treat. } \\
\text { Group }\end{array}$ & $\begin{array}{l}\text { Control } \\
\text { Group }\end{array}$ & $\begin{array}{l}\text { Diff. in } \\
\text { Means }\end{array}$ & & $\begin{array}{l}\text { Treat. } \\
\text { Group }\end{array}$ & $\begin{array}{r}\text { Control } \\
\text { Group }\end{array}$ & $\begin{array}{l}\text { Diff. in } \\
\text { Means }\end{array}$ & & \\
\hline \multicolumn{10}{|c|}{ COHS Treatment and Comparison 2 (self-pay) } \\
\hline Gestation in weeks & 39.57 & 39.68 & -0.11 & $* * *$ & 39.39 & 39.61 & -0.22 & 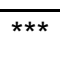 & -0.10 \\
\hline Birth weight in grams & 3371 & 3387 & -15.52 & *** & 3365 & 3389 & -24.50 & *** & -8.98 \\
\hline Month PNC Began & 3.33 & 3.27 & 0.06 & *** & 2.77 & 3.12 & -0.36 & *** & -0.42 \\
\hline First Trimester $=1$ & $62.3 \%$ & $63.9 \%$ & $-1.6 \%$ & *** & $75.1 \%$ & $67.5 \%$ & $7.6 \%$ & & $9.2 \%$ \\
\hline LBW $(<2500 \mathrm{gr})=1$ & $4.6 \%$ & $4.9 \%$ & $-0.3 \%$ & *** & $4.5 \%$ & $4.8 \%$ & $-0.3 \%$ & & $0.0 \%$ \\
\hline$x \operatorname{LBW}(<1000 \mathrm{gr})=1$ & $0.3 \%$ & $0.3 \%$ & $0.0 \%$ & & $0.3 \%$ & $0.4 \%$ & $0.0 \%$ & *** & $0.0 \%$ \\
\hline Premature $(<37 \mathrm{wks})=1$ & $8.3 \%$ & $8.7 \%$ & $-0.4 \%$ & $\star \star \star *$ & $8.3 \%$ & $8.7 \%$ & $-0.4 \%$ & 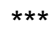 & $0.0 \%$ \\
\hline Very Premature $(<33$ wks $)=1$ & $1.4 \%$ & $1.6 \%$ & $-0.2 \%$ & *** & $1.3 \%$ & $1.6 \%$ & $-0.2 \%$ & *** & $-0.1 \%$ \\
\hline \multicolumn{10}{|c|}{ PC Treatment and Comparison 1 (Medi-Cal FFS) } \\
\hline Gestation in weeks & 39.47 & 39.71 & -0.24 & $* * *$ & 39.28 & 39.59 & -0.31 & $* * *$ & -0.07 \\
\hline Birth weight in grams & 3336 & 3383 & -47.09 & $* * *$ & 3339 & 3393 & -53.41 & $* * *$ & -6.32 \\
\hline Month PNC Began & 3.08 & 3.32 & -0.24 & $* * *$ & 2.62 & 3.08 & -0.46 & 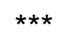 & -0.22 \\
\hline First Trimester $=1$ & $67.6 \%$ & $62.7 \%$ & $4.9 \%$ & $* * *$ & $76.9 \%$ & $68.5 \%$ & $8.4 \%$ & $* * *$ & $3.5 \%$ \\
\hline LBW $(<2500 \mathrm{gr})=1$ & $5.6 \%$ & $5.0 \%$ & $0.7 \%$ & $* * *$ & $5.5 \%$ & $4.8 \%$ & $0.8 \%$ & *** & $0.1 \%$ \\
\hline$x \operatorname{LLW}(<1000 \mathrm{gr})=1$ & $0.4 \%$ & $0.3 \%$ & $0.1 \%$ & *** & $0.4 \%$ & $0.4 \%$ & $0.1 \%$ & $* * *$ & $0.0 \%$ \\
\hline Premature $(<37$ wks $)=1$ & $9.5 \%$ & $8.8 \%$ & $0.7 \%$ & *** & $9.9 \%$ & $8.5 \%$ & $1.4 \%$ & 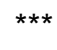 & $0.7 \%$ \\
\hline Very Premature $(<33$ wks $)=1$ & $1.8 \%$ & $1.6 \%$ & $0.2 \%$ & $* * *$ & $1.8 \%$ & $1.5 \%$ & $0.2 \%$ & *** & $0.0 \%$ \\
\hline
\end{tabular}

Notes:

$1 /{ }^{*}$ significant at $10 \% ;{ }^{* *}$ significant at $5 \% ;{ }^{* * *}$ significant at $1 \%$

2/ Two-Plan Counties (TPC), County Organized Health Systems (COHS) represent the two main managed-care plan types in California.

3/ Diff. $=$ difference; Treat. $=$ Treatment; FFS=fee-for-service

4/ Triple difference is calculated by subtracting the double difference of the last group from the middle group. 
Table 8: COHS Group Year and Zipcode Fixed Effects Difference in Differences Regressions

Without Propensity Score Common Support (NO PS) and with Propensity Score Common Support (PS)

\begin{tabular}{|c|c|c|c|c|c|c|c|c|c|c|c|c|}
\hline & \multicolumn{2}{|c|}{ Month Start } & \multicolumn{2}{|c|}{ First Trimester } & \multicolumn{2}{|c|}{ LBW } & \multicolumn{2}{|c|}{ xLBW } & \multicolumn{2}{|c|}{ Premature (<37 weeks) } & \multicolumn{2}{|c|}{ Very Premature $(<33$ weeks } \\
\hline & NOPS & PS & NOPS & PS & NOPS & PS & PS & NOPS & PS & NOPS & PS & NOPS \\
\hline \multicolumn{13}{|c|}{ COHS Treatment and Comparison 2 (self-pay) - Average Impact of Mandate } \\
\hline MC & $-0.168^{* \star \star}$ & $-0.148^{* \star \star}$ & $0.037^{* * *}$ & $0.034^{\star \star \star}$ & -0.002 & -0.001 & -0.001 & $-0.001^{*}$ & -0.002 & -0.002 & -0.001 & -0.001 \\
\hline (std error) & {$[0.017]$} & {$[0.018]$} & {$[0.004]$} & {$[0.005]$} & {$[0.002]$} & [0.002] & {$[0.001]$} & {$[0.001]$} & {$[0.003]$} & [0.003] & {$[0.001]$} & [0.001] \\
\hline$\%$ ? Dependent Variabl e & $-5.05 \%$ & $-4.46 \%$ & $5.94 \%$ & $5.45 \%$ & $-4.38 \%$ & $-2.19 \%$ & $-29.53 \%$ & $-29.53 \%$ & $-2.42 \%$ & $-2.42 \%$ & $-7.10 \%$ & $-7.10 \%$ \\
\hline \multicolumn{13}{|c|}{ COHS Treatment and Comparison 2 (self-pay) - Pooled Year Impacts } \\
\hline MC & $-0.125^{\star \star \star}$ & $-0.101^{* \star \star}$ & $0.027^{\star \star \star}$ & $0.024^{\star \star \star}$ & -0.003 & -0.002 & $-0.001^{*}$ & $-0.001^{\star \star}$ & -0.003 & -0.002 & -0.001 & -0.002 \\
\hline (std error) & {$[0.018]$} & {$[0.019]$} & {$[0.005]$} & {$[0.005]$} & {$[0.002]$} & {$[0.002]$} & {$[0.001]$} & {$[0.001]$} & {$[0.003]$} & {$[0.003]$} & {$[0.001]$} & [0.001] \\
\hline MC*year3+ & $-0.121^{\star \star *}$ & $-0.132^{* * *}$ & $0.027^{\star \star *}$ & $0.029^{\star \star *}$ & 0.002 & 0.003 & 0 & 0.001 & 0.001 & 0 & $0.002^{*}$ & $0.003^{* *}$ \\
\hline (std error) & {$[0.018]$} & {$[0.019]$} & {$[0.005]$} & {$[0.005]$} & {$[0.002]$} & {$[0.002]$} & {$[0.001]$} & {$[0.001]$} & {$[0.003]$} & {$[0.003]$} & {$[0.001]$} & [0.001] \\
\hline$\%$ ? DV MC & $-3.75 \%$ & $-3.04 \%$ & $4.33 \%$ & $3.85 \%$ & $-6.57 \%$ & $-4.38 \%$ & $-29.53 \%$ & $-29.53 \%$ & $-3.62 \%$ & $-2.42 \%$ & $-7.10 \%$ & $-14.21 \%$ \\
\hline \% ? DV MC*year3+ & $-7.39 \%$ & $-14.08 \%$ & $8.67 \%$ & $8.49 \%$ & $-2.19 \%$ & $2.19 \%$ & $0.00 \%$ & $0.00 \%$ & $-2.42 \%$ & $-3.62 \%$ & $7.10 \%$ & $7.10 \%$ \\
\hline \multicolumn{13}{|c|}{ COHS Treatment and Comparison 2 (self-pay) - Per Year Impact of Mandate } \\
\hline MC*year1 & -0.084 & $-0.054^{\star *}$ & 0.016 & 0.009 & 0 & 0 & -0.001 & $-0.001^{*}$ & -0.002 & -0.002 & -0.002 & -0.002 \\
\hline (std error) & {$[0.023]^{\star \star \star}$} & {$[0.025]$} & {$[0.006]^{\star \star \star}$} & {$[0.006]$} & {$[0.003]$} & {$[0.003]$} & {$[0.001]$} & {$[0.001]$} & {$[0.004]$} & {$[0.004]$} & [0.002] & [0.002] \\
\hline (std error) & {$[0.020]^{\star \star \star}$} & [0.022] & {$[0.005]^{* * *}$} & {$[0.006]$} & {$[0.002]^{\star *}$} & {$[0.003]$} & {$[0.001]^{* *}$} & {$[0.001]$} & {$[0.003]$} & {$[0.004]$} & {$[0.001]$} & [0.001] \\
\hline$M C^{\star}$ year3 & -0.201 & $-0.199^{* * *}$ & 0.044 & $0.044^{* \star *}$ & -0.002 & 0.001 & -0.001 & -0.001 & -0.004 & -0.004 & 0 & 0 \\
\hline (std error) & {$[0.024]^{\star \star \star}$} & {$[0.026]$} & {$[0.006]^{\star * *}$} & {$[0.007]$} & {$[0.003]$} & {$[0.003]$} & {$[0.001]$} & {$[0.001]$} & {$[0.004]$} & {$[0.004]$} & {$[0.002]$} & [0.002] \\
\hline$M C^{*}$ year4 & -0.282 & $-0.259^{\star \star \star}$ & 0.067 & $0.063^{\star \star \star}$ & -0.002 & -0.001 & -0.001 & 0 & 0 & 0.001 & 0.001 & 0.002 \\
\hline (std error) & {$[0.025]^{\star \star *}$} & {$[0.028]$} & {$[0.007]^{\star \star *}$} & {$[0.007]$} & {$[0.003]$} & {$[0.003]$} & {$[0.001]$} & {$[0.001]$} & [0.004] & {$[0.004]$} & {$[0.002]$} & [0.002] \\
\hline $\mathrm{MC}^{*}$ year5 & -0.345 & $-0.319^{\star \star \star}$ & 0.077 & $0.072^{\star \star \star}$ & 0.001 & 0.002 & -0.001 & -0.001 & 0.003 & 0.003 & 0.001 & 0.001 \\
\hline (std error) & {$[0.028]^{\star \star *}$} & {$[0.031]$} & {$[0.007]^{\star \star *}$} & {$[0.008]$} & {$[0.003]$} & {$[0.004]$} & {$[0.001]$} & {$[0.001]$} & {$[0.004]$} & {$[0.005]$} & {$[0.002]$} & [0.002] \\
\hline$M C^{*}$ year6 & $-0.305^{\star \star \star}$ & $-0.302^{* \star *}$ & $0.062^{* \star \star}$ & $0.062^{* \star *}$ & -0.002 & -0.001 & $-0.002^{* \star}$ & $-0.002^{\star *}$ & 0 & 0 & -0.002 & 0 \\
\hline (std error) & {$[0.029]$} & {$[0.031]$} & {$[0.007]$} & {$[0.008]$} & {$[0.003]$} & {$[0.004]$} & {$[0.001]$} & {$[0.001]$} & {$[0.005]$} & {$[0.005]$} & {$[0.002]$} & [0.002] \\
\hline$\%$ ? MC*year6 & $0.87 \%$ & $-9.10 \%$ & $9.95 \%$ & $9.94 \%$ & $-4.38 \%$ & $-2.19 \%$ & $-59.07 \%$ & $-59.07 \%$ & $0.00 \%$ & $0.00 \%$ & $-14.21 \%$ & $0.00 \%$ \\
\hline Mean Dependent Variable & 3.33 & 3.32 & 0.623 & 0.624 & 0.046 & 0.046 & 0.003 & 0.003 & 0.083 & 0.083 & 0.014 & 0.014 \\
\hline Number of Observations & \multicolumn{6}{|c|}{ Without a common propensity score: 251,503} & \multicolumn{6}{|c|}{ With a common propensity score support 228,530} \\
\hline
\end{tabular}

Notes:

$1 /$ The coefficient for the MC variable gives the impact. Year3+ is a dummy if county has had managed care for 3 or more years.

$2 / \mathrm{MC}^{*}$ year $1=$ impact from being on the mandate 1 year etc.

$3 /{ }^{*}$ significant at $10 \% ;{ }^{* *}$ significant at $5 \% ;{ }^{* * *}$ significant at $1 \%$

4/ Two-Plan Counties (TPC), County Organized Health Systems (COHS) represent two managed-care plan types in California.

$5 /$ Mean dependent variable is the mean of the dependent variable for the treated in the preintervention period.

$6 / \%$ ? is the percentage change of the impact. 
Table 9

TPC Group Year and Zipcode Fixed Effects Difference in Differences Regressions Without Propensity Score Common Support (NO PS) and with Propensity Score Common Support (PS)

\begin{tabular}{|c|c|c|c|c|c|c|c|c|c|c|c|c|}
\hline & \multicolumn{2}{|c|}{ Month Start } & \multicolumn{2}{|c|}{ First Trimester } & \multicolumn{2}{|c|}{ LBW } & \multicolumn{2}{|c|}{ xLBW } & \multicolumn{2}{|c|}{$\begin{array}{c}\text { Premature } \\
(<37 \text { weeks })\end{array}$} & \multicolumn{2}{|c|}{$\begin{array}{l}\text { Very Premature } \\
\text { (<33 weeks) }\end{array}$} \\
\hline & NOPS & PS & NO PS & PS & NOPS & PS & NO PS & PS & NOPS & PS & NOPS & PS \\
\hline \multicolumn{13}{|c|}{ TPC Treatment and Comparison 1 (Medi-Cal FFS) with Comparison 2 and 4 Triple Differences - Average Impact of Mandate } \\
\hline Mandate & $-0.027^{\star \star}$ & -0.024 & $0.007^{\star \star}$ & 0.005 & -0.001 & $-0.004^{*}$ & -0.001 & -0.001 & $-0.004^{*}$ & $-0.008^{* * *}$ & 0 & -0.001 \\
\hline (std error) & [0.012] & {$[0.017]$} & [0.003] & {$[0.004]$} & {$[0.002]$} & {$[0.002]$} & {$[0.000]$} & {$[0.001]$} & [0.002] & [0.003] & {$[0.001]$} & {$[0.001]$} \\
\hline Mean DV & 3.08 & 3.09 & 0.676 & 0.674 & 0.056 & 0.054 & 0.004 & 0.004 & 0.095 & 0.093 & 0.018 & 0.017 \\
\hline \%? DV & $-0.88 \%$ & $-0.78 \%$ & $1.04 \%$ & $0.74 \%$ & $-1.79 \%$ & $-7.41 \%$ & $-25.00 \%$ & $-25.00 \%$ & $-4.21 \%$ & $-8.60 \%$ & $0.00 \%$ & $-5.88 \%$ \\
\hline \multicolumn{13}{|c|}{ TPC Treatment and Comparsion 1 (Medi-Cal FFS) with Comparison 2 and 4 Triple Differences - Per Year Impact of Mandate } \\
\hline MC & $-0.035^{\star \star *}$ & $-0.038^{* *}$ & $0.009^{* \star *}$ & $0.007^{*}$ & -0.001 & -0.003 & -0.001 & -0.001 & $-0.004^{*}$ & $-0.008^{* \star *}$ & 0 & -0.001 \\
\hline (std error) & [0.012] & {$[0.017]$} & [0.003] & {$[0.004]$} & {$[0.002]$} & [0.002] & {$[0.000]$} & {$[0.001]$} & [0.002] & {$[0.003]$} & {$[0.001]$} & {$[0.001]$} \\
\hline MC*year3+ & $0.073^{* \star *}$ & $0.090^{* * *}$ & $-0.017^{* * *}$ & $-0.015^{\star * *}$ & $-0.004^{* \star *}$ & $-0.003^{*}$ & 0 & 0 & 0.001 & 0.001 & -0.001 & -0.001 \\
\hline (std error) & [0.010] & [0.014] & [0.003] & [0.004] & [0.001] & [0.002] & {$[0.000]$} & {$[0.001]$} & [0.002] & [0.002] & {$[0.001]$} & {$[0.001]$} \\
\hline$\%$ ? DV MC & $-1.14 \%$ & $-1.23 \%$ & $-1.33 \%$ & $1.04 \%$ & $0.00 \%$ & $-5.56 \%$ & $-25.00 \%$ & $-25.00 \%$ & $-4.21 \%$ & $-7.53 \%$ & $0.00 \%$ & $-5.88 \%$ \\
\hline \% ? DV MC*year3+ & $1.23 \%$ *** & $1.68 \%$ *** & $1.18 \%$ *** & $-1.19 \% *$ & $-8.93 \%$ *** & $-11.11 \%$ *** & $-25.00 \%$ & $-25.00 \%$ & $-3.16 \%$ & $-8.6 \%$ ** & $-5.56 \%$ & $-11.76 \%$ \\
\hline $\begin{array}{l}\text { Mean Dependent } \\
\text { Variable } \\
\text { Number of } \\
\text { observations }\end{array}$ & $\begin{array}{r}3.08 \\
\text { Without a } \\
\end{array}$ & $\begin{array}{c}3.09 \\
\text { nmon prop }\end{array}$ & $\begin{array}{c}0.676 \\
\text { sity score: }\end{array}$ & $\begin{array}{r}0.674 \\
51,638 \\
\end{array}$ & 0.056 & 0.054 & $\begin{array}{c}0.004 \\
\text { With a co } \\
\end{array}$ & non prope & sity score & $\begin{array}{c}0.093 \\
\text { pport: } 984 \\
\end{array}$ & 0.018 & 0.017 \\
\hline
\end{tabular}

Notes:

$1 /$ The coefficient for the MC variable gives the impact. Year3+ is a dummy if county has had managed care for 3 or more years.

$2 / \mathrm{MC}^{*}$ year1 = impact from being on the mandate 1 year etc.

$4 /{ }^{*}$ significant at $10 \% ;{ }^{* *}$ significant at $5 \% ;{ }^{* * *}$ significant at $1 \%$

$5 /$ FFS = fee-for-service

6/ Two-Plan Counties (TPC), County Organized Health Systems (COHS) represent two managed-care plan types in California.

7/ Mean DV is the mean of the dependent variable for the treated in the pre-intervention period.

$8 / \%$ ? is the percentage change of the impact. 